\title{
Gestão Social: notícias sobre o campo de estudos e práticas a partir das interações e debates do VI Enapegs
}

\author{
Patrícia Maria E. Mendonça \\ Centro Universitário da FEl \\ Sylmara Lopes Francelino Gonçalves-Dias \\ Universidade de São Paulo \\ Luciano A. Prates Junqueira \\ Pontifícia Universidade Católica de São Paulo
}

Este texto busca relatar a realização do evento Encontro Nacional da Rede de Pesquisadores em Gestão Social (Enapegs), que teve sua última edição em maio de 2012, em São Paulo. Para tanto, busca delimitar o que vem a ser o campo de estudos sobre Gestão Social, a constituição da Rede de Pesquisadores em Gestão Social (RGS), bem como a dinâmica de construção e realização do Enapegs e suas principais discussões e resultados, que no último encontro teve como temática: Gestão Social: mobilizações e conexões.

Palavras-chave: Gestão Social; Enapegs; redes; conhecimento; práticas.

Gestión Social: noticias sobre el campo de estudio y práctica de las interacciones y los debates del VI Enapegs

Este trabajo tiene como objetivo relatar la realización del Enapegs- Encuentro Nacional de la Red de Investigadores en Gestión Social, que tuvo su última edición, celebrada en mayo de 2012, en San Pablo. Por lo tanto, trata de delimitar lo que viene a ser el campo de los estudios sobre Gestión Social, la creación de la Red de Investigadores en Gestión Social (RGS), así como la dinámica de la construcción y realización del Enapegs y sus principales discusiones y resultados, que en el último encuentro tuvo como tema: Gestión Social: mobilizaciones y conexiones.

Palabras clave: Gestión Social; Enapegs; redes; conocimientos; prácticas.

Social Management: news about the field of study and practice from the interactions and discussions of the VI Enapegs

This paper seeks to report the event National Meeting of the Network of Researchers in Social Management (Enapegs) which had its last edition held in May 2012, in São Paulo. Therefore, it seeks to 
delimit the field of studies on Social Management, the establishment of the Network of Researchers in Social Management (RGS) as well as the dynamics of construction and completion of the Enapegs and its main discussions and results, which has had the last meeting's theme: Social Management: mobilizations and connectivity.

KEY WORDS: Social Management; Enapegs; networks; knowledge; practices.

\section{Introdução}

Nos últimos anos, reflexões coletivas de pesquisadores engajados com os temas da gestão pública e políticas sociais, democracia e espaço público, economia social e cooperativismo, desenvolvimento e territórios, responsabilidade social e ação social das empresas, sociedade civil e organizações sociais, entre outros, têm gerado intenso debate em torno do campo de Gestão Social no Brasil. Afinal, toda gestão é social, pois ela se dá em espaços de relações, espaços que são plurais e diversos, por vezes antagônicos (França Filho, 2008; Fisher, 2002). Daí a ênfase na dimensão social de gestão, que por ser um ato relacional não está limitada ao espaço da organização empresarial ou das relações econômicas.

O termo Gestão Social, como vem sendo utilizado por pesquisadores, reunidos na Rede de Pesquisadores em Gestão Social (RGS), tem como objeto de estudo a gestão de problemáticas sociais e ambientais que necessitam de uma visão intersetorial e interorganizacional, considerando seu espaço de articulação em um contexto de constante fortalecimento democrático, onde múltiplos atores compartilham interesses, visões e ações dentro de um território.

A construção desse campo de conhecimento vem acontecendo no contexto brasileiro desde a abertura democrática e consolidação de diversas políticas públicas, em especial as sociais, em que espaços de participação e interação têm sido criados, permitindo a entrada de diferentes atores da sociedade civil, bem como de setores empresariais e públicos, que não apenas participam desse espaço, como também criam seus próprios espaços de articulação de experiências sociais e produtivas, ou de articulação intersetorial (Dowbor, 1999, 2010). Há também a experimentação em diferentes áreas de práticas organizativas, como economia solidária, empreendimentos sociais, desenvolvimento local, inovações em políticas públicas, entre outras.

Até o início da década de 1990, pelo menos no campo da administração, os debates sobre Gestão Social no Brasil se restringiam às organizações do chamado Terceiro Setor (Tenório, 2009). Ao final daquela década esse debate já se encontrava bem mais ampliado, não apenas na administração, como em outras áreas. O debate sobre Gestão Social torna-se central no campo do serviço social (Maia, 2005), ocorrendo também em outras áreas das ciências sociais, economia, comunicação.

Para Carrion e Calou (2007:15), no prefácio de uma das publicações que buscam articular práticas e conceitos sobre Gestão Social, a gestão, historicamente, e da forma como foi consolidada enquanto campo de estudos no Brasil, concentrou-se em ações que buscavam o "uso racional de recursos para a realização de fins econômicos". A gestão, nessa perspectiva, é pri- 
mordialmente o campo de estudos e práticas em que se busca mobilizar um conjunto de "ativos" a partir de regras, procedimentos e medidas que promovam a maximização de retornos.

A lógica da gestão empresarial naturalmente leva à prevalência de decisões centradas nos interesses privados, enquanto a Gestão Social se constitui na esfera pública, onde os interesses não são unicamente econômicos, mas também sociais, políticos, humanos e ambientais. Nesse sentido, a ação social que resulta da gestão tanto pode ser resultante da intervenção do Estado para garantir direitos sociais como da ação das organizações sem fins lucrativos, que contribuem na execução das políticas sociais (Junqueira, 2004).

Ênfase também é dada, por Fischer (2002:14), no caráter relacional e multiescalar da gestão, definindo a Gestão Social como um "ato relacional que se estabelece entre pessoas, em espaços e tempos relativamente delimitados, objetivando realizações e expressando interesses de indivíduos, grupos e coletividade". A gestão pressupõe que tensões estarão presentes na construção e desconstrução de lideranças e mandatos, em processos sempre permeados de ambiguidades e contradições. Além disso, a ação gestora é produzida por indivíduos ou coletividades, em microunidades organizacionais, mas também em organizações com alto grau de hibridismo e complexidade, quer sejam ONGs, fundações empresariais, programas e projetos interinstitucionais ou formatos mais fluidos, como movimentos sociais.

Tal como descreveu Tenório (2009:2): “[...] uma gestão ampliada na qual o processo decisório seria vinculante ao diálogo consciente, procedimental, por meios dos diferentes atores da sociedade, sob a perspectiva de sujeitos em ação". E para reforçar a dissociação com o terceiro setor e projetos sociais com a Gestão Social, o mesmo autor afirma tratar-se de "processo gerencial dialógico no qual a autoridade decisória é compartilhada entre os participantes da ação (ação que possa ocorrer em qualquer tipo de sistema social — público, privado ou de organizações não governamentais)".

Dentro dessa perspectiva, Araújo (2012) esclarece que o social como adjetivo é atribuído às organizações e à gestão, às formas de empreendedorismo e às tecnologias, de modo proposital, ganhando uma agenda própria nas instituições tipicamente produtoras de conhecimento, em especial as universidades, bem como no campo político, nas organizações estatais e da sociedade civil, numa tentativa de coprodução do bem público. Conquanto o termo Gestão Social ainda careça de contornos mais precisos de definição, já se pode reconhecê-lo como uma categoria polissêmica, cujo sentido desafia a ideia da gestão como termo associado apenas a produtividade, desempenho e controle. Sendo uma ação humana, o ato de gerir mobiliza recursos variados de forma organizada: capital, pessoas, matéria-prima e tecnologia logo são lembrados; mas não se pode mais se esquecer do conhecimento como fator fundamental do desenvolvimento de qualquer sociedade. Como organizar a criação, difusão e multiplicação do conhecimento?

\section{A Rede de Pesquisa em Gestão Social (RGS) e o Enapegs}

Em 2007, um grupo de pesquisadores se reuniu, na cidade de Juazeiro do Norte, Ceará, na Universidade Federal do Ceará, Campus Cariri, para a realização do I Encontro Nacional de 
Pesquisadores em Gestão Social (I Enapegs), com a temática "Práticas em debate, teorias em construção". Era justamente o momento de buscar delimitar e construir um espaço de produção, sistematização e circulação dos debates que estavam ocorrendo. De certa forma, este grupo, composto em grande maioria por pesquisadores ligados a escolas de administração, se via sem um locus para seus debates (Silva Jr., 2007).

As discussões sobre as temáticas sociais predominavam com enfoque na gestão das organizações do Terceiro Setor, ou nas ações sociais de empresas. Havia outras discussões no campo da administração pública, principalmente com relação às políticas sociais e ambientais. No entanto, o grupo entendia que a Gestão Social não acontecia separadamente, nas organizações da sociedade civil, nos governos e suas políticas, ou nas empresas, mas em espaços de articulação entre eles (Silva Jr., 2007). O primeiro encontro buscou refinar estes entendimentos e a partir dele foi produzido o livro Gestão Social: práticas em debate, teorias em construção (Silva Jr. et al., 2008).

O diferencial que se pode notar na gênese inicial do Enapegs foi seu caráter descentralizador dos grandes centros, pois a primeira edição aconteceu em um campus universitário de uma cidade do interior do estado do Ceará, na região Nordeste do país. O evento, entretanto, era apenas uma iniciativa, que reunia e permitia o suporte a uma série de outras atividades que constroem e delimitam o conhecimento em um determinado campo do saber. Nesse sentido, é importante compreender o que determinou o surgimento da Rede de Pesquisadores em Gestão Social (RGS), conforme o relato de Paula Schommer (2008:1):

Contar a história da construção de uma rede é desafiador. Primeiro, porque são histórias, no plural. Histórias de pessoas, grupos, organizações que, em algum momento, lugar e razão, se cruzam e estreitam laços entre si, compartilham interesses, repertórios e objetivos, interagem com mais intensidade, atam mais forte os nós. Em outros momentos, se distanciam, agregam-se a outras redes, mais tarde retornam, já diferentes. A rede vai acontecendo, transformando-se, em seu próprio rumo e ritmo. A rede é viva, a história segue acontecendo. E cada novo elemento permite reinterpretar o que já se viveu.

Difícil também é escolher de onde começar, pois quando pensamos nas ligações dessa rede, quem estava ligado a quem, por que motivo, quando,... a história vai longe. Além do mais, se outra pessoa contar a sua versão, alguns detalhes serão esquecidos, outros lembrados, enfim, diferentes histórias têm espaço na narração "da história".

Schommer (2008) considera que um marco inicial da RGS tenha sido uma reunião que aconteceu em novembro de 2003, em São Paulo, na Escola de Administração de Empresas de São Paulo da Fundação Getulio Vargas (Eaesp-FGV), na qual se discutiu a criação de uma rede de pesquisadores ou de uma associação em torno de temáticas como Gestão Social, desenvolvimento local e afins. A reunião foi articulada por várias pessoas, sobretudo os professores Tânia Fischer (UFBA), Peter Spink (Eaesp), Fernando Tenório (Ebape), Luciano Junqueira (PUC-SP) e José Antonio Pinho (UFBA), dispondo de uma rede de colegas e parceiros que já atuavam em conjunto em diferentes iniciativas. A ideia era contar com pesquisadores e 
gestores seniores, ao lado de novos integrantes, tanto jovens acadêmicos como gestores de organizações que lidam com temáticas similares fora da academia.

No convite feito por Tania Fischer, em 2003, para esta reunião já estavam impressos os contornos e a agenda da RGS.

Esta instituição — associação — seria mais que uma rede e deveria ter características mais inclusivas do que as atuais associações nacionais de programa de pós-graduação. Nesse entendimento, uma associação deste tipo deveria orientar-se por (a) critérios de inclusão, ou seja, acolher instituições e pessoas envolvidas com o tema, sem discriminação de origem institucional; (b) institucionalização regimental e registro, de forma que seja mais do que uma rede; mas preservando-se flexibilidade e qualidade; (c) um elenco de atividades compartilhadas como eventos, e publicações, redes de informação e outros (Fisher, 2003).

Nessa reunião, houve intenso debate sobre vantagens e desvantagens de cada alternativa — uma associação formal ou uma rede mais fluida, sem formalização. Decidiu-se pela criação da Associação Brasileira de Gestão Social para o Desenvolvimento Local. Discutiu-se motivadores, elementos de identidade entre as pessoas que a propunham naquele momento, eixos temáticos em torno dos quais se pretendia trabalhar, objetivos, desenho institucional, critérios de afiliação e pertencimento e estratégias de articulação. Schommer (2008) diz que da reunião de 2003 todos saíram "com o firme propósito de estabelecer a entidade formalmente".

Na história que se seguiu, porém, a formalização não ocorreu, embora a maior parte daquelas pessoas continuasse ligada de algum modo à RGS. Não se sabem as razões exatas pelas quais não prosseguiu o trabalho no caminho da constituição formal da Associação.

Afinal, o que entendemos por representar a Rede de Pesquisadores em Gestão Social (RGS)? Ao responder a esta indagação, Schommer (2012) diz que o site da RGS (e as informações lá contidas) não é a rede (são importantes para a consolidação da produção, para a comunicação, para divulgação dos projetos, mas não é a rede em si). O Enapegs não é a rede, é o principal evento no âmbito da Rede, é o que promove mais conexões entre os nós, promove discussão do campo, mas também não é a Rede.

As redes, no universo de mudanças, surgem como uma linguagem de vínculos, de relações sociais entre organizações que interagem mediadas por atores sociais que buscam entender de maneira compartilhada a realidade social. São formas de agir que privilegiam os sujeitos, que de maneira interativa apropriam o conhecimento dos problemas sociais e sua solução. Essa realidade complexa e autoproduzida permite falar do caráter interdisciplinar da Gestão Social, que integra saberes orientados para a solução de problemas que afetam pessoas, organizações e a realidade social onde se inserem.

Nessa perspectiva, uma rede como a RGS é diversa e múltipla, em certa medida intangível e incontrolável e aí está sua riqueza. Assim, a RGS "é fruto das múltiplas, dinâmicas e cotidianas interações que acontecem entre nós e tantas pessoas que se dedicam ao tema, usando ou não a sigla e o site, talvez sequer conscientes de que fazem parte de uma Rede, de um campo de conhecimento" (Schommer, 2012). 


\section{0 Enapegs}

É dentro deste contexto que o Enapegs tem sido realizado anualmente, desde 2007, no âmbito da Rede de Pesquisadores em Gestão Social (RGS — www.rgs.wiki.br). O Enapegs foi criado por iniciativa de jovens pesquisadores sobre o tema, advindos do Centro Interdisciplinar de Desenvolvimento e Gestão Social da Universidade Federal da Bahia (Cigas/UFBA), que naquele momento estavam em diferentes instituições de ensino, com seus respectivos grupos de pesquisa e laboratórios. Cabe destacar a atuação dos professores Jeová Torres (UFC-Cariri), Airton Cardoso Cançado, do Núcleo de Economia Solidária (NeSol) da Universidade Federal do Tocantins (UFT), e Paula Chies Schommer, associada ao Ciags/UFBA e atualmente professora da Universidade do Estado de Santa Catarina (Udesc).

Inicialmente, os Enapegs foram organizados e sediados fora do eixo das grandes capitais, em cidades em que começavam a se expandir e se institucionalizar novos centros e grupos de pesquisa sobre Gestão Social, o que, de certo modo, colaborou para legitimálos (Araújo, 2012). Porém, em 2011 e 2012, os encontros foram realizados em capitais, primeiro em Santa Catarina e depois em São Paulo. O evento busca manter seu caráter itinerante e descentralizador. Através desta dinâmica tem sido possível colocar os pesquisadores da área em contato com diferentes realidades brasileiras, convivendo com suas paisagens, culinária e observando um pouco de suas características socioeconômicas tão distintas (Schommer, 2011).

Em 2012 aconteceu a sexta edição nas dependências da Pontifícia Universidade Católica de São Paulo (PUC-SP). A realização do evento em um grande centro como São Paulo, com toda a sua movimentação econômica, cultural e social, acentuou a expectativa de crescimento e expansão do Enapegs tanto no número de participantes, quanto no de trabalhos apresentados. O histórico destes seis anos de existência do evento já denota que o Enapegs tornou-se o espaço de discussão, proposição e desenvolvimento da temática da Gestão Social no Brasil. O quadro 1 expõe essa evolução, mostrando como vem se consolidando desde sua criação em 2007.

Em 2007, na carta convite para o I Enapegs, Silva Junior (2007) destacava a existência de centros de pesquisas sobre a Gestão Social e temas afins (economia solidária, desenvolvimento territorial, terceiro setor, responsabilidade social, entre outros) nas principais universidades do país. Por outro lado, apontava restritos espaços para publicação em periódicos e eventos científicos regulares para discussão dos trabalhos acadêmicos afeitos ao campo de Gestão Social. Nesse sentido, caberia ao Enapegs a ampliação do ambiente para o debate aprofundado desse tema, assim como da difusão de conhecimentos e práticas relativas a essa modalidade de gestão e áreas afins. 


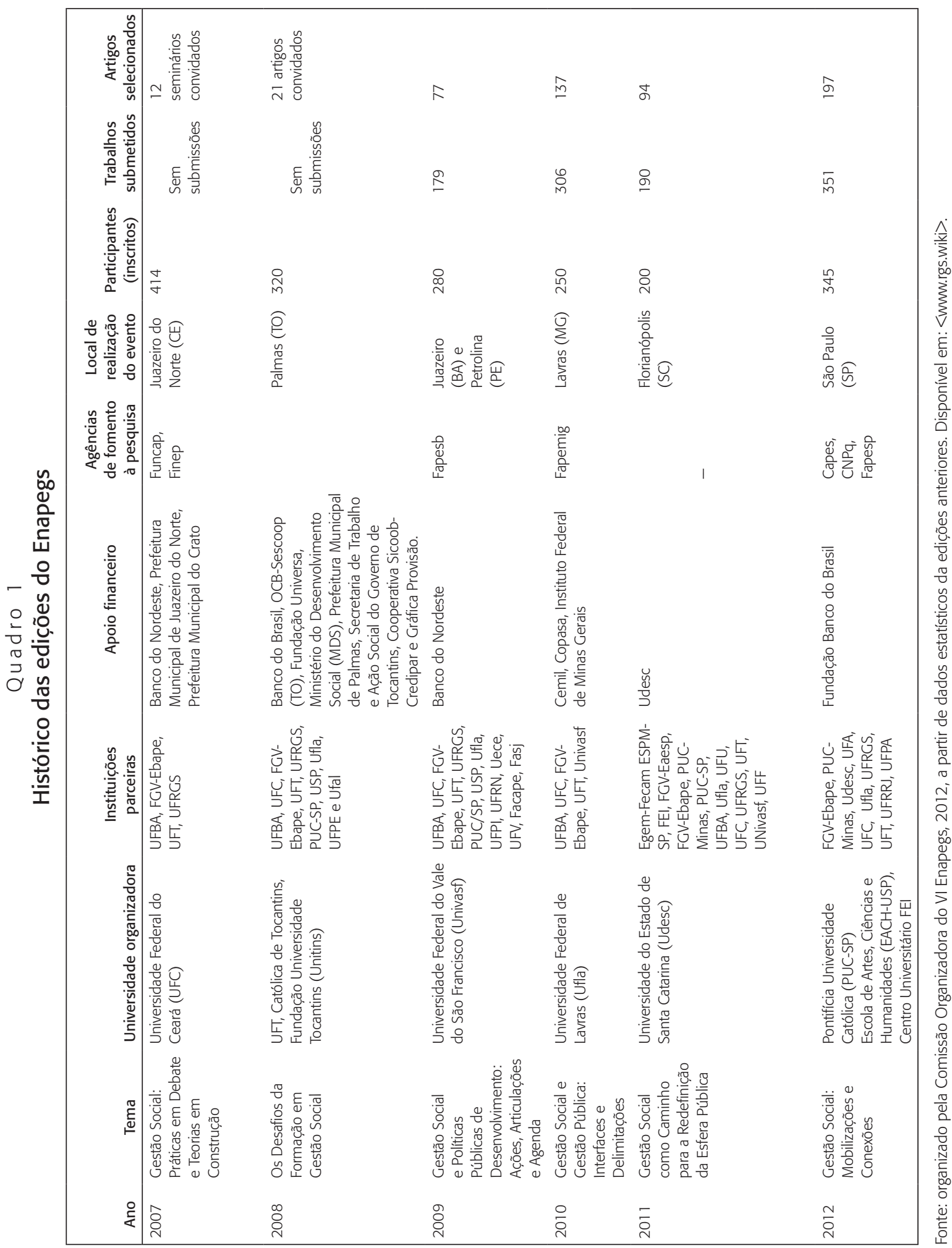

Rev. Adm. Pública - Rio de Janeiro 46(5):1391-408, set./out. 2012 
Até a segunda edição, o evento convidava os trabalhos a serem apresentados. A terceira edição do Enapegs, em 2009, marca a abertura de chamada de trabalhos, com a presença de pesquisadores oriundos de 36 instituições de ensino. Na edição de 2010, em Lavras, ocorre um aumento no número de trabalhos recebidos e a participação de 45 instituições de ensino, demonstrando o impulso de crescimento da área. Esse foi um momento de debates importantes com destaque para a proposta de uma pesquisa nacional acerca de ensino em Gestão Social, as diretrizes curriculares para o campo de Gestão Pública e Gestão Social, o andamento das ações dos projetos em Gestão Social relacionados ao edital Pró-Administração, da Capes, e, finalmente, a discussão sobre o formato do Enapegs.

Em 2011, imaginou-se um Enapegs diferente: um evento menor e mais integrativo. Menor porque não assumiria a função de discussão de toda a gama de produção científica em Gestão Social (apenas alguns eixos temáticos abriram chamadas de trabalhos). Integrativo, visto que seu formato foi imaginado para dar espaço às pessoas para conversarem e colocarem em pauta suas necessidades, seus projetos e suas intenções para o futuro da Gestão Social. Esta ideia do formato mais integrativo não fez com que a edição de 2011 fosse menor, em termos de participação, diversidade e trabalhos recebidos, do que as edições anteriores.

Na sexta edição, em 2012, o Enapegs chega a São Paulo. A construção dessa edição envolveu um longo processo que começou em 2011, quando a RGS elegeu São Paulo como a cidade sede do VI Enapegs. A PUC-SP foi a instituição que acolheu o encontro em suas instalações, destacando-se nesse trabalho o papel do Núcleo de Estudos Avançados do Terceiro Setor (Neats) e da Coordenadoria de Estudos e Projetos Especiais (Cedepe), contando com a participação de alunos, professores e pesquisadores de graduação e pós-graduação em administração e serviço social. Adicionalmente, a organização do VI Enapegs contou com a coordenação conjunta do Centro Universitário da FEI e da Escola de Artes, Ciências e Humanidades da Universidade de São Paulo (EACH/USP), que também envolveram seus respectivos quadros docentes e discentes.

A partir de diretrizes da RGS, a sexta edição do Enapegs teve como tema central "Gestão Social: Mobilizações e Conexões". Todos os participantes foram convidados a pensar a gestão como um processo que se dá à medida que atores sociais diversos se mobilizam, a partir de diferentes conexões para defenderem ou executarem ideias e formas de gestão dialógicas, participativas e transformadoras. A ideia de mobilizações e conexões passava também pelo fato de o evento estar se realizando em São Paulo, um centro pulsante, onde encontros e cruzamentos são promovidos nas mais diversas áreas.

A partir dessa diretriz, a comissão científica definiu as questões que norteariam os trabalhos da edição 2012: quais ações representam mobilizar e conectar pessoas? Qual o nível e quais práticas de articulações entre organizações do Estado, do mercado e da sociedade civil demonstram ou poderão demonstrar a gestão como processo dialógico? E, por fim, qual a agenda proposta para a Gestão Social, quer na formulação de políticas públicas, quer naquelas relações de caráter produtivo?

A tabela 1 representa a distribuição dos trabalhos submetidos e aceitos por eixo temático na edição de 2012 . 
Tabela 1

Distribuição dos trabalhos por eixo temático - Enapegs 2012

\begin{tabular}{|clrc|}
\hline \multicolumn{1}{|c}{ Tema } & Submissões & Aprovados \\
\hline 1 & Economia solidária e cooperativismo & 55 & 30 \\
2 & Gestão Social, políticas públicas e território & 150 & 88 \\
3 & Movimentos sociais e Gestão Social na construção democrática & 35 & 20 \\
4 & Ensino, pesquisa e extensão em Gestão Social & 39 & 17 \\
5 & Sustentabilidade, mercado e sociedade & 51 & 21 \\
6 & Inovações e tecnologias sociais & 21 & 18 \\
Total de submissões (artigos e relatos de práticas) & 351 & 194 \\
\hline
\end{tabular}

Fonte. Comissão organizadora do VI Enapegs.

Nas cinco primeiras edições dos Enapegs, a maior parte dos trabalhos apresentados estava relacionada à questão das políticas públicas e coprodução na esfera pública (Pinto et al., 2012). Dessa forma, pelas temáticas abordadas nas seis edições do Enapegs percebe-se uma tendência a uma forte aproximação e convergência dos campos da Gestão Social com as políticas públicas. Em 2012, dos 194 artigos aprovados, 88 estão no eixo temático Gestão Social, políticas públicas e território.

Se por um lado essa inclinação parece benéfica no sentido de um maior interesse e aproximação entre gestão pública e Gestão Social, é necessário alargar as fronteiras do debate em Gestão Social. Foi com o intuito de ampliar as conexões interdisciplinares do campo de Gestão Social que neste sexto Enapegs foram convidados palestrantes da América Latina (Marcelo Fernando Lopes Parra, do Instituto de Altos Estudios Nacionales de Equador, e Plabo MonjeRyes, do Centro de Estudios y Analisis de Políticas Públicas de la Universidad do Chile); da França (Claudine Offredi, da Faculté d'Économie de Grenoble) e da Espanha (Joan Subirats, da Universidad Aberta de Barcelona).

\section{Consolidação e ampliação do campo da Gestão Social}

Entre os princípios constituintes da RGS está o envolvimento em ações e projetos de lideranças da área social e ambiental, por isso o evento busca uma aproximação da comunidade acadêmica com as organizações que trabalham diretamente com a geração de trabalho e renda, ONGs, fundações, institutos e órgãos governamentais responsáveis pela implementação, manutenção e monitoramento das políticas públicas voltadas para a promoção do desenvolvimento social. A própria estrutura de coordenação dos Enapegs reflete a proposta de compreensão do conceito de Gestão Social como processo dialógico, inclusivo e mobilizador. O encontro entre aqueles que pesquisam e os que têm realizado projetos e ações tem possibilitado sinergias positivas aos envolvidos. Para estimular a presença dos praticantes do campo, o evento aceita, 
além de artigos acadêmicos, trabalhos no formato denominado Relatos de Práticas. Os Relatos de Práticas têm o intuito de abrir espaço para o compartilhamento de aprendizagens decorrentes de experiências vivenciadas em Gestão Social, sejam elas desenvolvidas por governos, organizações da sociedade civil, movimentos sociais, empresas, universidades, indivíduos ou na interação entre essas. Outro formato que aceita propostas para submissão é o das Oficinas, que buscam também realizar a integração com prática-reflexão, especialmente no que tange às metodologias "integrativas" que têm sido aplicadas em diferentes cursos de formação em Gestão Social (Giannella, 2008).

Além destes formatos, o evento também abre espaço para os trabalhos de alunos de graduação (TCCs e ICs), recebendo e avaliando de forma diferenciada estes trabalhos no intuito de formar novos pesquisadores (Cançado, 2011). A tabela 2 apresenta os resultados por formato de trabalho apresentados em cada uma das edições.

Tabela 2

Total de trabalhos apresentados por formato e edição do Enapegs

\begin{tabular}{|lccrrrr|}
\hline Trabalhos Apresentados & 2007 & 2008 & 2009 & 2010 & 2011 & 2012 \\
\hline Artigos Completos & 12 & 21 & 69 & 107 & 64 & 160 \\
Artigos TCC-IC & & & & 7 & 18 & 21 \\
Relatos de Práticas & & & & 7 & 18 & 21 \\
Oficinas & & & 8 & 8 & 5 & 3 \\
Total Geral & 12 & 21 & 77 & 137 & 94 & 197 \\
\hline
\end{tabular}

Fonte: Comissões Organizadoras do Enapegs.

A cada ano, percebe-se o crescimento do número de participantes e o aumento do número de trabalhos, relatos, oficinas e pesquisas produzidos por professores, estudantes de graduação e pós-graduação, gestores de organizações estatais e da sociedade civil. Na edição de 2012 do Enapegs estiveram presentes aproximadamente 350 pesquisadores de 58 instituições de ensino superior oriundos de 17 estados brasileiros.

\section{Aprendizados coletivos e trabalho em rede}

A RGS realiza constantemente discussões sobre o andamento dos trabalhos e sua estruturação em rede. No último Enapegs foi novamente posta a questão da manutenção da RGS como uma rede informal. Mais uma vez optou-se por sua não formalização, considerando a dinâmica, flexibilidade e laços que unem os pesquisadores e suas instituições.

De fato, a RGS se configura de modo diferenciado, estabelecendo e assumindo relações entre seus membros, tendo em conta uma diversidade de posicionamentos teóricos, políticos e ideológicos sobre o tema. Redes articulam pessoas e instituições visando a construção, em 
parceria, de um objeto comum. Ao indicar que as interações possíveis de ocorrer são as mais distintas possíveis - saberes e contribuições diversas, relações interpessoais, interorganizacionais, intergovernamentais e intersetoriais - , a RGS constrói um espaço de trocas, que conta com a história e a contribuição de cada organização e de seus diversos atores, articulando pesquisadores em Gestão Social e suas respectivas instituições, de modo que as realizações dessa rede, em particular dos eventos, não resultem de uma atuação isolada, mas da integração de saberes e práticas de seus componentes.

A experiência coletiva de organização do VI Enapegs demonstrou as dificuldades e recompensas de se trabalhar de forma compartilhada, um processo de construção coletiva. Não é fácil lidar com muitas opiniões, a necessidade de incluir, ouvir, esperar, e aliar isto ao fato de que cada vez mais são exigidos tempos e prazos muitos restritos para os processos de produção acadêmica.

\section{Avanço, ampliação e aprofundamento do conhecimento sobre Gestão Social}

A delimitação do campo da Gestão Social tem sido debatida entre pesquisadores brasileiros na última década. Por um lado, a utilização do termo tem levado à sua banalização e, por outro, tem estimulado seu desenvolvimento como campo de conhecimento científico dentro das ciências sociais aplicadas (Cançado et al., 2011). Nesses termos, a Gestão Social vem-se consolidando enquanto campo de práticas, conhecimentos e atuação profissional, que, não por acaso, precocemente vêm-se institucionalizando (Boullosa e Schommer, 2008).

Assim, progressivamente, têm-se a ascensão de programas de formação em nível de extensão, pós-graduação (lato e stricto sensu) e graduação (tecnológica e bacharelado), centro de pesquisa, publicações, eventos e outras materializações do que se designou chamar por Gestão Social. O quadro 2 apresenta um balanço dos centros e núcleos dedicados ao tema.

Quadro 2

Balanço dos centros e núcleos dedicados ao estudo da Gestão Social

\begin{tabular}{|c|c|c|c|}
\hline Centro ou núcleo de estudo & Instituição sede & Coordenador & Ano de criação \\
\hline $\begin{array}{l}\text { Centro Interdisciplinar de Desenvolvimento } \\
\text { e Gestão Social (Ciags) }\end{array}$ & UFBA & Tânia Fischer & $1986^{1}$ \\
\hline $\begin{array}{l}\text { Programa de Estudos em Gestão Social } \\
\text { (Pegs) }\end{array}$ & Ebape-FGV & Fernando Tenório & 1990 \\
\hline Centro de Estudos do Terceiro Setor (Cets) & Eaesp-FGV & Luiz Carlos Merege & 1994 \\
\hline $\begin{array}{l}\text { Centro de Empreendedorismo Social e Ad- } \\
\text { ministração em Terceiro Setor (Ceats) }{ }^{2}\end{array}$ & $\begin{array}{l}\text { Programa Faculdade de Economia e } \\
\text { Administração (USP) }\end{array}$ & Rosa Maria Fischer & 1998 \\
\hline $\begin{array}{l}\text { Núcleo Interdisciplinar de Pesquisas e Estu- } \\
\text { dos sobre o Terceiro Setor da (Nipets) }\end{array}$ & $\begin{array}{l}\text { Programa de Pós-Graduação em } \\
\text { Administração (UFRGS) }\end{array}$ & $\begin{array}{l}\text { Rosinha Machado Car- } \\
\text { rion }\end{array}$ & 1998 \\
\hline
\end{tabular}




\begin{tabular}{|c|c|c|c|}
\hline Centro ou núcleo de estudo & Instituição sede & Coordenador & Ano de criação \\
\hline $\begin{array}{l}\text { Núcleo de Estudos Avançados do Terceiro } \\
\text { Setor (Neats) }\end{array}$ & $\begin{array}{l}\text { Programa de Estudos Pós-graduados } \\
\text { em Administração (PPGA/PUC-SP) }\end{array}$ & $\begin{array}{l}\text { Luciano Antônio Prates } \\
\text { Junqueira e Ladislau } \\
\text { Dowbor }\end{array}$ & 1998 \\
\hline $\begin{array}{l}\text { Núcleo de Pesquisa em Ética e Gestão Social } \\
\text { (Nupegs) }\end{array}$ & PUC-MG & $\begin{array}{l}\text { Armindo dos Santos } \\
\text { de Souza Teodósio e } \\
\text { Roberto Patrus Mundim } \\
\text { Pena }\end{array}$ & 2003 \\
\hline $\begin{array}{l}\text { Laboratório Interdisciplinar de Estudos em } \\
\text { Gestão Social (Liegs) }\end{array}$ & $\begin{array}{l}\text { Universidade Federal do Ceará - } \\
\text { Campus Cariri (UFC-Cariri) }\end{array}$ & Jeová Torres da Silva Jr. & 2006 \\
\hline Núcleo de Economia Solidária da (NESol). & UFT & Airton Cançado & 2006 \\
\hline $\begin{array}{l}\text { Núcleo de Estudos em Administração Pública } \\
\text { e Gestão Social (Neapegs) }\end{array}$ & UFLA & $\begin{array}{l}\text { José Roberto Pereira e } \\
\text { Ana Alice Villas Boas }\end{array}$ & 2007 \\
\hline $\begin{array}{l}\text { Núcleo Interdisciplinar de Estudos e Tecno- } \\
\text { logias em Gestão Social da (Nigs) }\end{array}$ & Univasf & $\begin{array}{l}\text { Ariadne S. Rigo e José } \\
\text { Raimundo Cordeiro } \\
\text { Neto }\end{array}$ & 2008 \\
\hline
\end{tabular}

1 O Ciags foi precedido pelo Núcleo de Estudos em Poder e Organizações Locais (Nepol), da Escola de Administração (EA) da UFBA.

2 Anteriormente denominado Centro de Estudos em Administração do Terceiro Setor.

3 Anteriormente denominado Núcleo de Estudos de Administração do Terceiro Setor.

Fonte: A partir de Cançado (2011) e Araújo (2012).

Em 2008, a Capes lançou o Programa de Apoio ao Ensino e à Pesquisa Científica e Tecnológica em Administração - Pró-Administração, com o objetivo de realizar projetos interinstitucionais entre os programas de pós-graduação em administração, onde constava como uma das áreas prioritárias a Gestão Social (Capes, 2008). Atualmente, a existência de cursos de extensão, graduação, especialização e mestrados em Gestão Social também evidencia a institucionalização do campo de conhecimento, conforme mostra o quadro 3.

Quadro 3

\section{Quadro resumo de cursos de graduação e pós-graduação em Gestão Social no Brasil}

\begin{tabular}{|c|c|c|c|}
\hline Curso & Instituição & Local & Ano de início \\
\hline $\begin{array}{l}\text { Mestrado Multidisciplinar e Profissional } \\
\text { em Desenvolvimento e Gestão Social }\end{array}$ & Ciags/UFBA & Salvador (BA) & 2007 \\
\hline $\begin{array}{l}\text { Mestrado Profissional em Gestão Social, } \\
\text { Educação e Desenvolvimento Local }\end{array}$ & Centro Universitário UNA & Belo Horizonte (MG) & 2008 \\
\hline $\begin{array}{l}\text { Graduação Tecnológica em Gestão } \\
\text { Pública e Gestão Social }\end{array}$ & Ciags/UFBA & Salvador (BA) & 2010 \\
\hline $\begin{array}{l}\text { Graduação em Administração Pública } \\
\text { (Gestão Pública e Social) }\end{array}$ & $\begin{array}{l}\text { Universidade Federal do Ceará - Campus } \\
\text { Cariri (UFC) }\end{array}$ & $\begin{array}{l}\text { Juazeiro do Norte } \\
\text { (CE) }\end{array}$ & 2011 \\
\hline
\end{tabular}




\begin{tabular}{|c|c|c|c|}
\hline Curso & Instituição & Local & Ano de início \\
\hline $\begin{array}{l}\text { Graduação em Administração Pública } \\
\text { e Social }\end{array}$ & $\begin{array}{l}\text { Universidade Federal do Rio Grande do Sul } \\
\text { - UFRGS }\end{array}$ & Porto Alegre (RS) & s.i. \\
\hline $\begin{array}{l}\text { MBA Gestão e Empreendedorismo } \\
\text { Social, Especialização em Avaliação de } \\
\text { Projetos e Programas Sociais }\end{array}$ & Fundação Instituto de Administração (FIA) & São Paulo (SP) & s.i. \\
\hline $\begin{array}{l}\text { Especialização em Gestão de Projetos } \\
\text { Sociais em Organizações do Terceiro } \\
\text { Setor }\end{array}$ & PUC-SP & São Paulo (SP) & s.i. \\
\hline $\begin{array}{l}\text { Especialização em Projetos Sociais: } \\
\text { Gestão e Perspectivas }\end{array}$ & Centro Universitário Senac & São Paulo (SP) & s.i. \\
\hline $\begin{array}{l}\text { Especialização em Gestão das Políticas } \\
\text { Sociais }\end{array}$ & Universidade Paulista (Unip) & São Paulo (SP) & s.i. \\
\hline $\begin{array}{l}\text { Especialização em Gestão Social: } \\
\text { Políticas Públicas, Redes e Defesa de } \\
\text { Direitos }\end{array}$ & $\begin{array}{l}\text { Universidade do Norte do Paraná (Unopar- } \\
\text { virtual) }\end{array}$ & $\begin{array}{l}\text { Ensino a distância } \\
\text { (EAD) }\end{array}$ & s.i. \\
\hline $\begin{array}{l}\text { Especialização em Gestão Social em } \\
\text { Políticas Públicas }\end{array}$ & Universidade Paranaense (Unipar) & Umuarama (PR) & s.i. \\
\hline Especialização em Gestão Social & Pareceira Sesi/Unidus/Unicemp & Curitiba (PR) & s.i. \\
\hline MBA em Gestão Social & Universidade Cândido Mendes (Ucam) & Rio de Janeiro (RJ) & s.i. \\
\hline $\begin{array}{l}\text { Especialização em Gestão de Iniciativas } \\
\text { Sociais }\end{array}$ & $\begin{array}{l}\text { Universidade Corporativa do Serviço Social da } \\
\text { Indústria (UniSesi) em parceria com UFRJ }\end{array}$ & $\begin{array}{l}\text { Ensino a distância } \\
\text { (EAD) }\end{array}$ & s.i. \\
\hline $\begin{array}{l}\text { Especialização em Política de Assistên- } \\
\text { cia Social e Gestão do Suas }\end{array}$ & $\begin{array}{l}\text { Escola Satélite (UFMG) em parceria com } \\
\text { Rede Pitágoras }\end{array}$ & $\begin{array}{l}\text { Ensino a distância } \\
\text { (EAD) }\end{array}$ & s.i. \\
\hline Especialização em Gestão Social & Fundação João Pinheiro & Belo Horizonte (MG) & s.i. \\
\hline $\begin{array}{l}\text { MBA em Gestão e Negócios do Desen- } \\
\text { volvimento Regional Sustentável }\end{array}$ & $\begin{array}{l}\text { Consórcio Ciags/Ufba e Ufla, Universidade } \\
\text { Federal do Mato Grosso (UFMT), Instituto } \\
\text { de Ensino e Pesquisa em Administração } \\
\text { (Inepad) }\end{array}$ & $\begin{array}{l}\text { Ensino a distância } \\
\text { (EAD) para funcio- } \\
\text { nários do Banco do } \\
\text { Brasil e Caixa }\end{array}$ & s.i. \\
\hline
\end{tabular}

Fonte: a partir de Araújo (2012) e sites das instituições.

Outra evidência da rápida institucionalização do campo é o surgimento de periódicos específicos sobre Gestão Social. O quadro 4 apresenta lista de periódicos especializados. 
Quadro 4

Lista de periódicos especializados em Gestão Social

\begin{tabular}{|c|c|c|}
\hline Periódico & Instituição sede & Ano do primeiro número \\
\hline Cadernos de Gestão Social & Universidade Federal da Bahia (Ciags/UFBA) & 2007 \\
\hline $\begin{array}{l}\text { APGS - Revista Administração Pública e } \\
\text { Gestão Social }\end{array}$ & Universidade Federal de Viçosa & 2009 \\
\hline $\begin{array}{l}\text { NAU Social - Revista Eletrônica da } \\
\text { Residência Social }\end{array}$ & $\begin{array}{l}\text { Universidade Federal da Bahia (Ciags/UFBA) e } \\
\text { Observatório da Formação em Gestão Social }\end{array}$ & 2010 \\
\hline $\begin{array}{l}\text { Rigs - Revista Interdisciplinar de Gestão } \\
\text { Social }\end{array}$ & Universidade Federal da Bahia (Ciags/UFBA) & $2012^{1}$ \\
\hline
\end{tabular}

Fonte: a partir de Araújo (2012).

'. Primeiro número está previsto para 2012.

Essas revistas, com exceção da última, já possuem qualificação e avaliação pela Capes segundo critério divulgado em 2012 (Capes, 2012). Isso demonstra um indício de expandir a produção do conhecimento sobre Gestão Social, porém, conforme observa Araújo (2012), existe uma concentração de 3 periódicos, ainda que com objetivos distintos, de um mesmo centro de pesquisa. Cabe destacar a inovadora proposta editorial da NAU Social e da Rigs ao recepcionar trabalhos para publicação em formatos de texto, imagem e som.

Também é importante destacar que o VI Enapegs recebeu apoio financeiro da Capes, CNPq e Fapesp. Desde o primeiro Enapegs é tradição do evento a publicação na forma de livro dos textos dos trabalhos, casos, conferência e informações complementares sobre o evento. Publicada pela universidade promotora de cada edição do Enapegs, a Série Editorial "Coleção Enapegs" já se encontra em seu quinto volume. ${ }^{1}$

Além do livro, são produzidos também os anais eletrônicos do evento, existindo ainda diversas parcerias com muitas revistas que publicam os melhores trabalhos do evento, algumas delas lançando números especiais com trabalhos do evento. Na sexta edição, 13 revistas indexadas receberão trabalhos indicados pela comissão científica do VI Enapegs.

\section{Considerações finais}

Buscamos discorrer aqui um pouco sobre os acontecimentos em torno da construção do campo de estudos denominado Gestão Social, e o papel da RGS e do Enapegs nesse processo, buscando enfatizar o que vem ocorrendo nesses encontros de área realizados anualmente.

\footnotetext{
${ }^{1}$ Veja maiores informações no site da RGS (<www.rgs.wiki.br>). O sexto volume, fruto da edição 2012, está em fase de produção.
} 
Adjetivar a gestão como social pode parecer uma redundância desnecessária, no entanto, foi uma escolha consciente de um grupo de pesquisadores que buscava desconstruir e destacar algumas noções acerca do que vem a ser o ato de gerir. Desconstruir, em primeiro lugar, uma noção que estava restrita a certos espaços e tipos de organizações (França Filho, 2008), e destacar algumas "novidades" acerca da gestão e seus desafios para atuar em prol de transformações sociais, que se materializam no contexto de democratização e ampliação dos atores que lidam e participam diretamente da discussão e da atuação social, seja em políticas públicas, em iniciativas de organizações da sociedade civil, ou em iniciativas do mercado.

O termo Gestão Social, como vem sendo utilizado por pesquisadores, reunidos na RGS, tem como objeto de estudo a gestão de problemáticas sociais e ambientais que necessitam de uma visão intersetorial e interorganizacional, considerando seu espaço de articulação em um contexto de constante fortalecimento democrático, onde múltiplos atores compartilham interesses, visões e ações dentro de um território.

De qualquer modo, esse é um movimento recente, que envolve diversos pesquisadores, na sua maioria concentrados em escolas de administração (tanto empresarial, quanto pública), mas que também congrega as áreas do serviço social, e mais timidamente outras áreas das ciências sociais, como sociologia, ciência política, psicologia, educação, comunicação, que pregam a interdisciplinaridade do campo e a necessidade de diálogos. Esses pesquisadores se congregaram em torno de uma rede, a RGS, que tem como principal objetivo promover interações e trocas entre pesquisadores e gestores ligados à temática da Gestão Social.

Em meio à recente trajetória da Gestão Social como campo de conhecimentos e práticas interdisciplinares, os Enapegs ocupam papel primordial. A cada edição, os encontros são palco de aproximação, estranhamento, identificação e ligação entre pessoas, experiências e ideias, que buscam compartilhar suas experiências, descobertas e dúvidas, explorando novos olhares sobre a Gestão Social (Schommer e Boullosa, 2011). Os encontros têm sido marcados por experimentações, como a descentralização, a adoção de formatos diferenciados de submissão (relatos de prática, trabalhos de graduação e oficinas), além de ter em seu próprio modelo de organização um formato diferenciado.

Se lembradas as edições realizadas até aqui - em Juazeiro do Norte (CE), Palmas (TO), Petrolina (PE) e Juazeiro (BA), Lavras (MG) e Florianópolis (SC), São Paulo (SP) —, uma das preocupações centrais do evento foi propiciar aos interessados pela Gestão Social um espaço de socialização. Não apenas de apresentação de suas produções científicas, mas também um ambiente - ainda que itinerante — no qual as pessoas pudessem encontrar-se e compartilhar experiências, saberes e conhecimentos.

A construção do conhecimento para a RGS não parece se centrar em desvendar os segredos do mundo, mas dialogar com eles, reconhecendo como inevitável a incerteza no interior da explicação científica. Essa perspectiva difere da prática da administração, pautada pela certeza, pela ordem. A complexidade e as incertezas da realidade social determinam que o pensamento positivo, marcado pelas certezas, ceda lugar às interações dinâmicas e às transformações. Assim, o que prevalece é o saber interdisciplinar, que possibilita criar um discurso, que se situa além das disciplinas particulares. A criatividade e a compreensão são mais importantes do que a certeza e a predição. 
De fato, a RGS se configura de modo diferenciado, estabelecendo e assumindo relações entre seus membros, considerando uma diversidade de posicionamentos teóricos, políticos e ideológicos sobre o tema. Redes articulam pessoas e instituições visando à construção, em parceria, de um objeto comum. Ao propor que as interações possíveis de ocorrer são as mais distintas possíveis - saberes e contribuições diversas, relações interpessoais, interorganizacionais, intergovernamentais e intersetoriais - , a RGS constrói um espaço de trocas, que conta com a história e a contribuição de cada organização e de seus diversos atores, articulando pesquisadores em Gestão Social e suas respectivas instituições, de modo que as realizações dessa rede, em particular dos eventos, não resultem de uma atuação isolada, mas da integração de saberes e práticas de seus componentes (Junqueira, 2008).

A experiência coletiva de organização do VI Enapegs demonstrou as dificuldades e recompensas de se trabalhar de forma compartilhada, um processo de construção coletiva. Não é fácil lidar com muitas opiniões, a necessidade de incluir, ouvir, esperar, e aliar isto ao fato de que cada vez mais são exigidos tempos e prazos muitos restritos para os processos de produção acadêmica. E podemos, afinal, "[...] aproveitar essa experiência na construção dos eventos para refletirmos, enquanto pesquisadores que somos, sobre os desafios da Gestão Social seus princípios, valores, metodologias, tecnologias e as maravilhas e desafios do trabalho em rede" (Schommer, 2012).

\section{Refêrencias}

ARAÚJO, Edgilson T. Consistências da Gestão Social e seus processos de formação: um campo em construção. Tese (doutorado em serviço social) - Pontifícia Universidade Católica de São Paulo, São Paulo, 2012.

BOULLOSA, Rosana F.; SCHOMMER, Paula C. Limites da natureza da inovação ou qual o futuro da Gestão Social? In: ENCONTRO NACIONAL DA ASSOCIAÇÃO DE PÓS-GRADUAÇÃO EM ADMINISTRAÇÃO, XXXII, 2008, Rio de Janeiro. Anais... Rio de Janeiro: Anpad, 2008.

CANÇADO, Airton C. Fundamentos teóricos da Gestão Social. Tese (doutorado em administração) — Universidade Federal de Lavras, Lavras, 2011.

CANÇADO, Airton C. et al. Gestão Social: conhecimento e produção científica nos Enapegs, 20072010. In: SCHOMMER, Paula C.; BOULLOSA, Rosana F. (Org.). Gestão Social como caminho para redefinição da esfera pública. Florianópolis: Udesc, 2011. v. 1, p. 167-190.

CAPES. Coordenação de Aperfeiçoamento de Pessoal de Nível Superior. Edital Pró-Administração $n^{\circ}$ 09/2008. Disponível em: < http://capes.gov.br/images/stories/download/bolsas/Edital_Pro_Administracao.pdf $>$. Acesso em: jun. 2012.

CAPES. Coordenação de Aperfeiçoamento de Pessoal de Nível Superior. Comunicado no 02/2012, área de Administração, Ciências Contáveis e Turismo, atualização do WebQualis da área. Disponível em: <http://qualis.capes.gov.br/arquivos/avaliacao/webqualis/criterios2010_2012/Criterios_Qualis_2011_27.pdf $>$. Acesso em: jun. 2012. 
CARRION, Rosinha S. M.; CALOU, Ângela. Prefácio — Pensar a Gestão Social em terras de "Padinho Cícero". In: SILVA JUNQUILHO, Gelson et al. (Org.). Tecnologias de Gestão por uma abordagem multidisciplinar. Vitória: Edufes, 2007. v. II, p. 159-170.

DOWBOR, Ladislau. Brasil: tendencias de la gestión social. Nueva Sociedad, n. 187, 2010. Disponível em: <http://dowbor.br>. Acesso em: 15 jun. 2012.

DOWBOR, Ladislau. Gestão Social e transformação da sociedade, 1999. Artigos on line. Disponível em: <http://dowbor.org/8_gestaosocial.asp>. Acesso em: 20 ago. 2009.

FISCHER, Tânia. Carta convite para reunião de pesquisadores na Eaesp-FGV. Comunicação pessoal. Salvador: UFBA, 24 nov. 2003. In: RGS. Quem somos. Site institucional da RGS, Florianópolis, 3 nov. 2008. Disponível em: <www.rgs.wiki.br/index.php/institucional/quem-somos.html>. Acesso em: 10 jun. 2012.

FISCHER, Tânia. Poderes locais, desenvolvimento e gestão: introdução a uma agenda. In: FISCHER, Tânia (Org.). Gestão do desenvolvimento e poderes locais: marcos teóricos e avaliação. Salvador: Casa da Qualidade, 2002. p. 12-32.

FRANÇA FILHO, Genauto C. Definindo a Gestão Social. In: SILVA JÚNIOR, Jeová Torres; MÂSIHET, Rogério Teixeira (Org.). Gestão Social: práticas em debate, teorias em construção. Fortaleza: Imprensa Universitária, 2008. v. 1, p. 26-37.

GIANNELLA, Valéria. Base teórica e papel das metodologias não convencionais para a formação em Gestão Social. In: CANÇADO, Airton C. et al. Os desafios da formação em Gestão Social. Palmas (TO): Provisão, 2008. p. 11-36.

JUNQUEIRA, Luciano A. P. Descentralização, intersetorialidade e rede na gestão da cidade. O\&S: Organizações \& Sociedade, Salvador, v. 11, n. 1, p. 129-139, 2004.

JUNQUEIRA, Luciano A. P. Gestão Social: organização, parcerias e redes sociais. In: CANÇADO, Airton C. et al. Os desafios da formação em Gestão Social. Palmas (TO): Provisão, 2008.

MAIA, Marilene. Gestão Social: reconhecendo e construindo referenciais. Revista Virtual Textos \& Contextos, n. 4, dez. 2005. Disponível em: <http://revistaseletronicas.pucrs.br/ojs/index.php/fass/ article/view/1010/790>. Acesso em: 5 mar. 2010.

PINTO, Áureo M. et al. Redes de colaboração científica: uma análise das publicações do Encontro Nacional de Pesquisadores em Gestão Social. In: ENCONTRO NACIONAL DE PESQUISADORES EM GESTÃO SOCIAL, ENAPEGS, VI, 2012, São Paulo. Anais... São Paulo: PUC-SP, 2012.

SCHOMMER, Paula; BOULLOSA, Rosana F. (Org.). Gestão Social como caminho para a redefinição da esfera pública. Florianópolis: Udesc, 2011. v. 1.

SCHOMMER, Paula. RGS. Quem somos. Site institucional da RGS, Florianópolis, 3 nov. 2008. Disponível em: <www.rgs.wiki.br/index.php/institucional/quem-somos.html>. Acesso em: 10 jun. 2012.

SCHOMMER, Paula. O que é a Rede de Pesquisadores em Gestão Social. Comunicação pessoal. Florianópolis: Udesc, jan. 2012. 
SILVA JUNIOR, Jeová T. Convite para o I Enapegs. Juazeiro do Norte (CE), 16 de abril de 2007. In: RGS. Quem somos. Site institucional da RGS, Florianópolis, 3 nov. 2008. Disponível em: <www. rgs.wiki.br/index.php/institucional/quem-somos.html>. Acesso em: 10 jun. 2012.

SILVA JUNIOR, Jeová T. et al. (Org.). Gestão Social: práticas em debate, teorias em construção. Fortaleza: Impressa Universitária/UFC, 2008. v. 1.

TENÓRIO, Fernando G. Gestão Social: uma réplica. Revista ADM. Made: Revista do Mestrado em Administração e Desenvolvimento Empresarial, Rio de Janeiro, ano 9, v. 13, n. 2, p. 1-4, maio/ago. 2009.

Patrícia Maria E. Mendonça é professora do Centro Universitário da FEI. E-mail: pmendonca@fei.edu.br. Sylmara Lopes Francelino Gonçalves-Dias é professora da Escola de Artes, Ciências e Humanidades da Universidade de São Paulo (USP). E-mail: sgdias@usp.br.

Luciano A. Prates Junqueira é professor titular da Pontifícia Universidade Católica de São Paulo (PUCSP). E-mail: junq@pucsp.br. 